\title{
Bio-energy and Rural Development: Findings from a Comparative Study in Central, Eastern and Southern Europe
}

Axel Wolz, Gertrud Buchenrieder, Richard Márkus*

Abstract:

Rising energy prices for fossil fuels, the unreliable supply of energy imports during recent winters, and European Union (EU) policies have stimulated national awareness and political action on renewable bio-energy among all of the European countries. In discussions on agricultural policy, renewable energy has been advocated as a way to more rural prosperity. In this paper, we assess whether there is any impact on agricultural and rural employment and income as anticipated. Among the new member states (NMS) of the EU, the share of bio-energy is slowly increasing. Yet among the Balkan states and Turkey this process has just started. In both sub-regions an expansion of rape seed cultivation, and to a smaller extent of the production of wood pellets, could be observed. Similarly, the build-up of processing facilities is in its infancy. Up to now, however, its overall impact on agricultural and rural income and employment seems to have been marginal.

Keywords: bio-energy, agricultural development, rural development, Central, Eastern and Southern Europe

JEL: Q10, Q28, Q42, R11

DOI: $10.2478 / v 10033-011-0011-1$

\section{Introduction}

Since the earliest history of mankind, people have relied on bio- and renewable energy to facilitate life. People made use of wood and, later on, of wind and water. However, in our times, the interest in renewable energy became more serious when the limits and environmental risks of fossil and nuclear energy became evident. Renewable energy was advertised not only as a way out of the limitations of fossil and nuclear energy, but also as a driver of rural prosperity, particularly for European farmers.

In our analysis we follow the definition of EUROSTAT, which defines renewable energy as the sum of specific forms of energies, i.e. hydropower, wind energy, solar energy, biomass and wastes and geothermal energy. Biomass and wastes cover organic, non-fossil material of biological origin that may be used for heat production, electricity generation and/or as a source of fuel. They comprise wood and wood waste, biogas, municipal solid waste and biofuels. Liquid biofuels mainly cover bioethanol (ethanol produced from biomass) and biodiesel (diesel produced from biomass or used fry oil) (Eurostat, 2009a).

We will focus on the use and expansion of biomass production for bio-energy, particularly in its "modern" forms, i.e. wood pellets and briquettes, municipal solid
* Axel Wolz
Leibniz Institute of Agricultural Development in
Central and Eastern Europe (IAMO)
E-mail:wolz@iamo.de

\section{Gertrud Buchenrieder}
Martin-Luther-University Halle (Saale), Universität der Bundeswehr Munich, Faculty of Politics and Social
Sciences

\section{Richard Márkus}
University of West Hungary, Faculty of Agriculture and Food Sciences 
waste, biogas and biofuels and their impact on agricultural and rural development in the region. The more "traditional" forms of bio-energy, i.e. the use of firewood, although still of high importance, will be touched on only briefly in this analysis. Regionally, the paper concentrates on two sub-regions, i.e. the new member states (NMS) ${ }^{1}$ of the EU and the Balkan states ${ }^{2}$ and Turkey, which might join the EU over time. The paper is based on 20 country reports that were prepared in 2009 within the "agripolicy project". The comparative statistical data refer to 2007.

\section{Role of Renewable Energy and Bio-energy in Total Energy Supply}

The use of renewable energy with respect to total energy demand in 2007 varies notably in the study region (Figure 1). Among the NMS, Malta and Cyprus have a very small share while in Latvia renewable energy constitutes more than a third of its total energy demand. All the other countries rely on this form of energy to some extent; for instance, Bulgaria, with a share of 4.9 percent, and Estonia with 12.4 percent. Hence the reliance on fossil fuels and nuclear energy is quite high. With respect to the Balkan states and Turkey, the picture looks quite different. For three countries, namely Bosnia \& Herzegovina, Montenegro and Albania, the share of renewable energy amounts to one fourth, or even one third of total energy demand. With respect to the other five countries the shares range from 8 to 11 percent. Subsequently, a first conclusion can be drawn: renewable energy has a certain share in the total energy demand, but in most countries of the study region it is not yet very important. In addition, renewable energy is a more important source of energy in the Balkan states and Turkey than in the NMS.

\footnotetext{
${ }^{1}$ The NMS comprise Estonia, Latvia, Lithuania, Poland, the Czech Republic, Slovakia, Hungary, Slovenia, Malta, Cyprus, Bulgaria and Romania.

${ }^{2}$ The Balkan states comprise Croatia, Serbia, Macedonia, Bosnia \& Herzegovina, Montenegro, Kosovo and Albania.
}

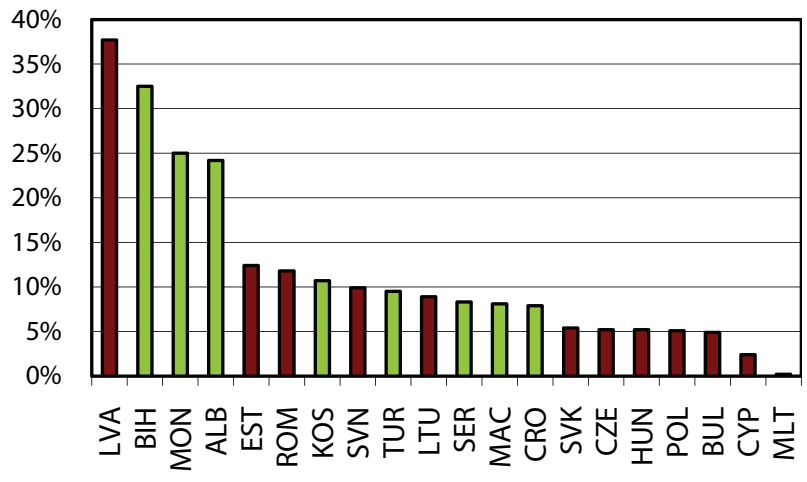

Source: EUROSTAT, 2009b and Country Reports, 2009 Figure 1: Share of renewable energy in total energy demand (\%), 2007

When looking at the share of bio-energy compared to total renewable energy, i.e. "traditional" (fire wood) plus "modern" forms (wood pellets and briquettes, biogas and biofuel), it becomes evident that in most countries of the region, "traditional" bio-energy is the most dominant source of renewable energy (Figure 2). In particular, among the NMS this source is very important. Only the small states of Malta and Cyprus cannot rely on bioenergy significantly for climatic reasons. In these two countries, solar power has become the major source of renewable energy. In the Balkan states and Turkey the use of bio-energy is important, but not as dominant as in the NMS. In most of the latter countries, (large-scale) hydropower dominates in the renewable energy sector.

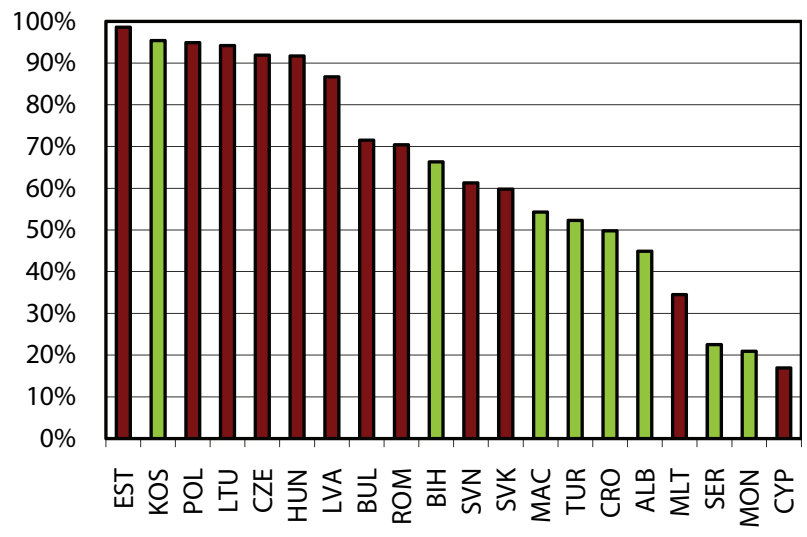

Source: EUROSTAT, 2009b and Country Reports, 2009

Notes: Bio-energy comprises traditionally wood and the modern forms which comprise wood pellets and briquettes, municipal solid waste, biogas and biofuels.

Figure 2: Share of bio-energy of total supply of renewable energy (\%), 2007 
As discussed above, the "traditional" forms of biomass have been used as a source of bio-energy since the earliest history of mankind. At this stage, we seek to deduce the share of "modern" forms of bio-energy within the total supply of bio-energy, i.e. the share of biofuel, biogas and municipal solid waste. Here, a sharp differentiation between the countries of the region can be made (Figure 3). In some countries it takes up a relatively high share, while in others it thusfar plays no role at all. While Malta is a special case (here mostly used cooking oil is refined to biodiesel), some Central European states show shares amounting to $10 \%$ or more. However, these states focus on different sources. Slovakia focuses on biofuel, while the Czech Republic has diversified its sources relatively equally on biofuel, municipal solid wastes and biogas. Hungary predominantly makes use of municipal solid wastes and Poland has focused on biofuel and biogas, so far. Among the other NMS, only in Lithuania (biofuel) and Slovenia (biogas) do the modern forms of bio-energy have some marginal relevance. With respect to the Balkan states and Turkey the "modern" forms of bio-energy are of no or only very modest relevance thusfar. Only Serbia (biofuel), Croatia (biofuel and biogas) and, to a very small extent, Turkey (biogas) have started to produce these "modern" forms of bio-energy. All other states within this sub-group are still in the planning phase of taking up the production of "modern" forms of bio-energy.

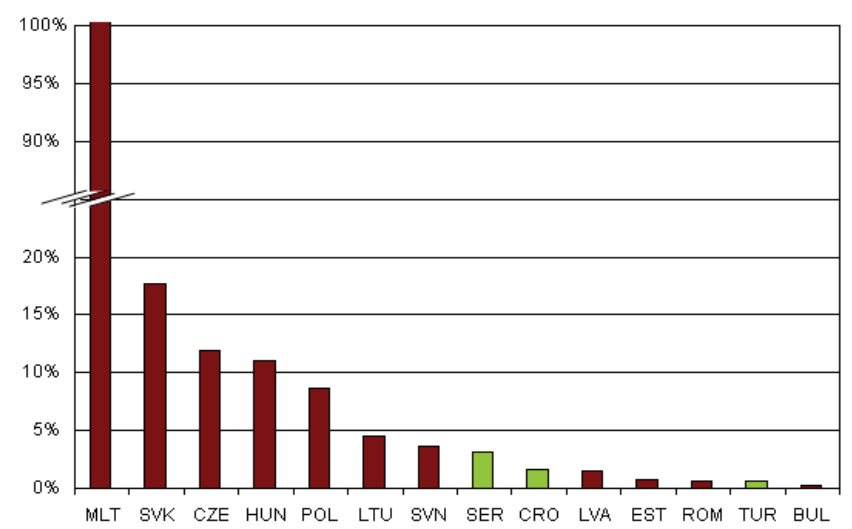

Source: EUROSTAT (2009b) and Country Reports 2009

Notes: The "modern" forms of bio-energy comprise wood pellets and briquettes, municipal solid waste, biogas and biofuels.

Figure 3: Share of "modern" forms to total supply of bio-energy (\%), 2007

In conclusion, it can be stated that, at this stage, the "modern" forms of bio-energy as portions of total national energy demand are still marginal. A few countries, i.e. Slovakia, the Czech Republic, Hungary and
Latvia, meet about a half percent of total demand. In another group of countries the share of "modern" forms of bio-energy is between 0.2 and 0.4 percent, i.e. Lithuania, Poland, Slovenia and Malta. In the remaining countries which have taken up "modern" forms of bioenergy production, the share just reaches maximally 0.1 percent, i.e. Estonia, Romania, Bulgaria, Serbia, Croatia and Turkey. In comparison, within the EU-15 the share of bio-energy in total energy demand is higher, e.g. in Germany it stood at 5.4 percent in 2007, while the share of renewable energy in total amounted to a relatively modest 7.2 percent (Ostermeyer and Pirscher, 2010).

\section{Impact of Bio-energy Production on Agricultural and Rural Development}

The expansion of bio-energy production as an important form of renewable energy is now actively promoted by all of the governments in the region, with three major objectives being pursued. First, the governments aim to decrease dependency on imports of fossil fuels and gas. Second, proponents of bio-energy expansion stress the positive energy balance of bioenergy production and the potential for cutting greenhouse gas emissions, particularly by reducing the need for lignite and coal. Third, an expansion of bioenergy production is seen as a potential source of employment and income for the agricultural sector in specific and rural areas in general (Zeller and Grass, 2008). This is an important policy goal as, for instance, 53 percent of all employment is rural among the NMS. However, there are counter-arguments claiming that bioenergy production actually yields less energy than it consumes in production and leads to higher greenhouse gas emissions. Similarly, it is doubtful whether any employment and income effects, particularly for smallscale farmers, will materialise at all (White and Dasgupta, 2010).

While national statistics show that modern forms of bio-energy are in their infancy, this article analyses whether there is already an observable impact on agricultural and rural development. However, it is difficult to measure and quantify the impact of bio-energy production with one indicator. Therefore, we will look at three sources of evidence. First, we assess whether the rising demand for bio-energy has led to changing cropping patterns and modern forms of wood production. Second, we look at whether the number of bio-energy processing plants has increased during recent 
years. Third, we will discuss experts' opinions about the possible impact of bio-energy production on agricultural and rural incomes and employment. While the first and second indicators rely on data for the period of 2000-2007 with a special emphasis on 2007, the third indicator is the outcome of expert interviews conducted during the spring of 2009 in the study region.

\subsection{Statistical Evidence on Production}

If the cropping patterns have changed towards so-called energy crops, this could be a first indication that bioenergy production is increasing. However, it is difficult to assess statistically the size of the area where energy crops are cultivated as, in general, they can mostly be used for human consumption and animal feed as well. Concerning the cropping patterns, not many changes could be observed up to now. Hence, we will rely on two proxy indicators. First, changes in agricultural production will be reported. Second, changes with respect to wood production are identified.

(1) In many countries, the area under rape seed cultivation has expanded rapidly during recent years (Table 1). While rape seed is also used in human consumption, we understand this rapid expansion also as an (indirect) indicator for the growing importance of bioenergy among farmers. Other crops are also used for bioenergy production, e.g. cereals including maize and sun flower, but the area under cultivation with respect to these crops did not change much during recent years. Hence, these crops did not seem to influence bio-energy production substantially up to now. The expansion in the cultivation of rape seed is seen by most farmers as a new source of income. Among the NMS, rape seed production also seems to have been encouraged by subsidies for energy crops by the EU. The increase of rape seed cultivation in the Balkan states and Turkey is not as impressive as in the NMS. However, rape seeds are not only processed at the national level, but, in case of limited national demand, exported to neighbouring countries, e.g. by Estonia. But the increase of the share of rape seeds in the crop rotation also brings a couple of repercussions to farmers, which have partly contradictory effects:

- improvement of crop rotation, leading to an increase of the yields of cereals (as reported from Latvia and Slovenia),

- reduction of fertilizer applications (Latvia) while others claim an increase in fertilizer and pesticide needs (Slovenia),
- drop in fixed machine costs due to better utilisation (Latvia). However, rape seed cultivation requires special technical know-how and special machines, hence specific additional investments, and

- reduction of soil erosion during winter seasons (Slovenia).

\begin{tabular}{|c|c|c|}
\hline & 2000 & 2007 \\
\hline \multicolumn{3}{|l|}{ New Member States } \\
\hline Lithuania & 0 & 124,800 \\
\hline Latvia & 6,900 & 99,200 \\
\hline Estonia & 28,800 & 73,600 \\
\hline Poland & 437,000 & 797,000 \\
\hline Czech Republic & 325,000 & 338,000 \\
\hline Slovakia & n.a. & 153,831 \\
\hline Hungary & 121,838 & 223,579 \\
\hline Slovenia & 122 & 5,358 \\
\hline Bulgaria & 9,500 & 54,000 \\
\hline Romania & 68,000 & $87,700^{*}$ \\
\hline \multicolumn{3}{|c|}{ Balkan states and Turkey } \\
\hline Croatia & 10,000 & 13,000 \\
\hline Turkey & 82 & 10,700 \\
\hline Serbia & 6,300 & 12,900 \\
\hline Bosnia \& Herzegovina & 0 & 1,578 \\
\hline
\end{tabular}

Source: Country Reports 2009

Note: n.a. = not available; ${ }^{*}$ 2005; MLT, CYP, MAC, MON, KOS, ALB: no energy crops

Table 1: Change of rape seed area under cultivation, 2000 - 2007 (ha)

These are several figures about the share of area under energy crops in general. Four country reports provide national figures; i.e. in Lithuania, Latvia and the Czech Republic their share amounts to about 5 percent and in Slovakia to about 3.3 percent. Six countries of the study region do not yet grow energy crops: Malta, Cyprus, Macedonia, Montenegro, Kosovo and Albania.

(2) The rising demand on bio-energy has not only implications on agricultural production and cropping patterns, but also on the use of wood. However, when looking in more detail at modern forms of wood energy production and use, the information available is even less. Some information about the production of wood pellets and briquettes as modern forms of wood energy is available. This is summarised in Table 2. A few countries reported that there is no pellet or briquette production from wood and wood waste. The major reasons seem to be that either there are no forests to exploit (e.g. Malta), or no investments in this source of bio-energy had been made due to high initial costs (e.g. Bulgaria, Romania, Montenegro, Kosovo and Albania). In a number of country reports no information has been given, hence it is 
not known whether there is any pellet/briquette production at all. Only Macedonia and Serbia report that pellet production has been taken up recently, but no figures have been given.

Only a few countries of the study region provided figures, but they show that pellet and briquette production are rapidly increasing. In particular, entrepreneurs in the Baltic states and some Central European countries are investing in this source of bioenergy. However, when producing wood pellets/briquettes, it does not necessarily mean than these "modern" forms of bio-energy are used in the respective countries. In particular, the Baltic states, as well as Croatia and Serbia, report that almost the whole of their production is exported. Bosnia \& Herzegovina exports about one third of its national production. Consequently, it can be concluded that "modern" forms of wood energy start playing a more prominent role in the analysed countries, while this source of bio-energy is not predominantly used in domestic markets, but is seen as an attractive export product.

\begin{tabular}{|l|l|l|}
\hline \multicolumn{2}{|l|}{2000} & 2007 \\
\hline New Member States & 270,000 & 547,000 \\
\hline Lithuania & $287,000^{*}$ & 461,000 \\
\hline Latvia & & $377,000^{* *}$ \\
\hline Estonia & $20,000^{* * *}$ & 350,000 \\
\hline Poland & $20,900^{*}$ & 102,000 \\
\hline Czech Republic & \multicolumn{2}{|l}{} \\
\hline Slovakia & $\leq 2,000$ & 41,000 \\
\hline Balkan states and Turkey & $3,200^{*}$ & 22,000 \\
\hline Croatia & & just started \\
\hline Bosnia \& Herzegovina & & just started \\
\hline Macedonia & & \\
\hline Serbia &
\end{tabular}

Source: Country Reports 2009

Note: * 2005, ${ }^{* *} 2006,{ }^{* * *}$ 2003; HUN, SVN, CYP, TUR: no information; MLT, BUL, ROM, MON, KOS, ALB: no production

Table 2: Change in the production of wood pellets/briquettes, 2000 - 2007 (tons)

Although biomass production for bio-energy is still in its infancy, all NMS, as well as increasingly the Balkan states and Turkey, are setting renewable energy targets which require higher production volumes of biogas and biofuel. However, to varying degrees all country reports emphasise a severe social repercussion: while in almost all countries of the region small scale farming predominates, rape seed production is, in general, taken up by larger farms (agricultural holdings) only. The reports on Bosnia \& Herzegovina and Kosovo where no energy crops are grown for the time being stress the fact that energy crop production might be a potential source of income only for large-scale farmers. A certain minimum size for cultivating these crops (in terms of area and economic size) seems to be necessary. As, in general, small scale farmers in the study region are reluctant to collaborate in order to increase economies of scale and their bargaining power, they are also not acceptable as input providers by (potential) biogas and biofuel producers. The country reports just mention two cases that tried to overcome this disadvantage: (1) In Latvia one cooperative was established in 2000 promoting rape seed production. It also invested in a biodiesel production plant that became operational in 2009. (2) In Croatia, a rape seed producer association has been recently established. However, in both cases no additional information has been provided. Similarly, in many countries of the study region large shares of forestry land are owned by farmers and other private individuals. Their plots, in general, are quite small. Hence, it is doubtful that they can provide sufficient wood for pellet and briquette production in an economically viable manner.

At this stage, it can be concluded that, although the data available is quite limited, the expansion of bioenergy production has had a very modest impact on the agricultural and forestry sectors. The only measurable change is the expansion of the cultivated area of rape seed and the expansion of wood pellet and briquette production. The area under other (potential) energy crops did not change much during recent years. Similarly, in many countries the area under fast growing trees has been expanded, albeit from a very low level, and statistical data has not been available.

\subsection{Expansion of Bio-energy Processing Facilities}

The second step analyses whether the build-up of modern forms of bio-energy supply have already started. Specifically, the enlargement of biogas and biofuel (i.e. biodiesel and bio-ethanol) production will be examined. First, the development of biogas production will be assessed. In both groups of countries analysed, the set-up of biogas plants and the use of biogas energy is a very recent development. The exceptions are Poland, Slovenia and Romania among NMS, where biogas production started during the 1980s, although Romania's production completely collapsed during the 1990s. Among the Balkan states Croatia, Macedonia and Serbia had their first biogas plants running during the 1980s, but none of 
these were operational anymore during the 1990s. Hence at the start of this millennium, just Poland, the Czech Republic and Slovenia among the NMS and Turkey among the second group had some biogas energy production. Most other countries started with this type of bio-energy during recent years. With the exception of Malta, Bulgaria and Romania all NMS have installed biogas plants by now. The reasons seem to be the limited supply of raw material for biogas (e.g. Malta) or limited financial resources available for investments (e.g. Bulgaria and Romania). The picture is quite different among the Balkan states and Turkey. Within that group just Croatia and Turkey have biogas plants running, while the other countries have yet to invest in this source of bio-energy. The scarce data about biogas plants are summarised in Table 3:

\begin{tabular}{|l|c|c|}
\hline & $\begin{array}{l}\text { Biogas } \\
\text { plants, total }\end{array}$ & $\begin{array}{l}\text { Biogas plants, } \\
\text { managed by } \\
\text { farmers }\end{array}$ \\
\hline New Member States & 6 & 1 \\
\hline Lithuania & 3 & 0 \\
\hline Latvia & n.a. & 0 \\
\hline Estonia & n.a. & n.a. \\
\hline Poland & 105 & 20 \\
\hline Czech Republic & 5 & 4 \\
\hline Slovakia & 40 & 5 \\
\hline Hungary & 9 & 9 \\
\hline Slovenia & 1 & 1 \\
\hline Cyprus & 13 & 3 \\
\hline Balkan states and Turkey & n.a. & n.a. \\
\hline Croatia & \multicolumn{2}{|l}{} \\
\hline Turkey & \multicolumn{1}{|l}{} \\
\hline
\end{tabular}

Source: Country Reports 2009

Note: n.a. = not available; other countries: no biogas production Table 3: Number of biogas plants, total and managed by farmers, 2007

With the exception of the Czech Republic and, to a smaller extent, Hungary, the number of operational biogas plants is quite small. Only in these two countries is biogas of some relevance as a source of energy. In all other countries of the region which have taken up biogas energy production, this source of energy is of marginal importance so far. However, particularly among those countries with sizable amounts of land and large agricultural areas, the potential seems to be very great. When looking at major sources of raw material for biogas energy, the agricultural sector at present only plays a supporting role. The major sources are:
- municipal waste water (Lithuania, Latvia, Poland, the Czech Republic)

- organic waste from the food industry (Lithuania, Slovakia, Cyprus, Turkey)

- household waste (Latvia, Poland).

Although on a very small scale, some farmers themselves have started investing in biogas production. These plants are predominantly fed with liquid manure and/or maize silage. However, almost all country reports stress the fact that the potential supply of manure and energy crops is much larger. In quite a number of countries there is idle land which could be used, e.g. for cultivating energy crops. The reasons for this rather low involvement of farmers seem to be:

- First, the financial aspect: Investment costs in biogas plants are rather high and the production of this form of energy is not competitive with respect to fossil sources of energy. Hence, investments are only made if there is financial support available. But most NMS have just started to provide such support within their national Rural Development Programmes, 2007-2013.

- The other factor seems to be a social one: Only large farms (agricultural enterprises) have enough raw materials at their disposal to run a biogas plant efficiently (i.e. only after having received financial support). However, in most countries of the region small-scale farming, or even subsistence farming, is predominant. Hence, most of the manure is needed as organic fertilizer, and even if available for biogas energy production, collecting the raw material from a large number of farms would be very costly.

In general, the energy produced by biogas plants is supplied as electricity. Just a small share of the produced energy is used for heating. As mentioned already, most countries have the potential to expand production of biogas. However, where biogas production is already ongoing, it is also emphasised that public resentment is growing due to bad smells and air pollution.

The other type of modern forms of bio-energy refers to biofuel, i.e. biodiesel and bioethanol. The production of biofuel is a very recent development in the study region. There had been some production in the Czech Republic during the 1990s that was later abandoned. In general, biofuel became an issue on the political agenda for NMS when joining the EU. With respect to the Balkan states and Turkey the option of biofuel became an issue with 


\begin{tabular}{|c|c|c|c|c|}
\hline & No. of companies & Production (t) & Share in diesel & Remarks \\
\hline \multicolumn{5}{|c|}{ New Member States } \\
\hline Lithuania & 3 & 26,000 & 4.5 & \\
\hline Latvia & 6 & 9,000 & 0.2 & exports \\
\hline Estonia & - & - & 0.2 & all imported \\
\hline Poland & 15 & 47,500 & 0.7 & \\
\hline Czech Rep. & 17 & 61,000 & 2.4 & \\
\hline Slovakia & n.a. & 46,000 & 0.1 & mostly exports \\
\hline Hungary & 2 & 7,000 & 1.2 & \\
\hline Slovenia & 3 & 11,000 & 1.2 & $50 \%$ exported \\
\hline Malta & 2 & 1,000 & 2.2 & \\
\hline Cyprus & 1 & 1,000 & 3.7 & imports \\
\hline Bulgaria & 20 & 9,000 & 0.1 & \\
\hline Romania & n.a. & 36,000 & - & \\
\hline \multicolumn{5}{|c|}{ Balkan-States and Turkey } \\
\hline Croatia & 2 & n.a. & 0.2 & imports \\
\hline Turkey & - & - & 0.5 & imports \\
\hline Serbia & 1 & 25,000 & 1.7 & \\
\hline Bosnia\&H & 1 & n.a. & 0.0 & \\
\hline
\end{tabular}

Source: Country Reports 2009; production figures for NMS: European Biodiesel Board (2009)

Note: n.a. = not available

Table 4: Production and share of biodiesel, 2007

the recent heavy price increases of fossil fuel and the discussion to reduce the production of greenhouse gases in line with the Kyoto Protocol.

With respect to biodiesel, most NMS have started biodiesel production between 2002 and 2004. Only Estonia has reported no production at all so far. However, it is importing some biodiesel. Among the second group of countries, Croatia started in 2006, while Macedonia, Serbia and Bosnia \& Herzegovina have taken up production more recently. Turkey seems to import some biodiesel, while in Montenegro, Kosovo and Albania biodiesel does not yet play any role. The scarce information provided by the country reports is summarised in Table 4.

In general, biodiesel is blended in diesel. The share is still relatively small, but especially among NMS it is planned that it will increase over time due to mandatory blending requirements as agreed by the EU. Among the Balkan states and Turkey the share of biodiesel is even smaller. Mostly, farmers use biodiesel themselves. The major source of biodiesel production is rape seed. In addition, waste from cooking oil is used as raw material (e.g. Malta, the Czech Republic, Cyprus, Croatia, Bosnia \& Herzegovina). In Macedonia since 2008, imported soybean oil is used for biodiesel production.

The production and use of bioethanol is still in its infancy among NMS. In Malta, Cyprus and Romania it is still of no relevance at all. Among the Balkan states and
Turkey bioethanol is not an issue at all so far. It is assumed that bioethanol production will go up in the next years due to mandatory blending requirements. Particularly, the Czech Republic recorded a big increase in national production, going up from $300 \mathrm{t}$ in 2007 to about $60,000 \mathrm{t}$ in 2008. However, in all countries bioethanol demand (like the demand for biodiesel) depends on national blending requirements and tax incentives. Otherwise both types of biofuel are not competitive with fossil fuels.

\subsection{Expert Assessments}

The data analysed so far show that there seem to be changes in cropping patterns, an expansion of wood pellet production and a start in biogas and biofuel production. However, the data do not allow for causal conclusion on the positive impact of bio-energy production on agricultural and rural development as claimed by its supporters. In order to get an idea, we relied on expert assessments in the respective countries. In each country up to ten national experts on renewable energy were asked to assess the employment and income effects of bio-energy in their respective countries. These experts were randomly selected among scientists and administrators. However, while there had been a rough common outline of key questions, their statements summarised below just provide a glance and are not 


\begin{tabular}{|l|l|l|l|l|}
\hline \multirow{5}{*}{ Employment } & \multicolumn{1}{|c|}{ High (4-5) } & \multicolumn{1}{c|}{ Somewhat (2-3) } & \multicolumn{1}{c|}{ None (0-1) } \\
\cline { 2 - 5 } & NMS & & $\begin{array}{l}\text { EST (3), HUN (3), SVN (3), POL } \\
(2), \text { CZE (2) }\end{array}$ & $\begin{array}{l}\text { LVA (1), MLT (1), CYP (1), } \\
\text { BUL (1), ROM (1) }\end{array}$ \\
\cline { 2 - 5 } & $\begin{array}{l}\text { Balkan-st. + } \\
\text { Turkey }\end{array}$ & TUR (4) & SER (3), BIH (3) & CRO (0), ALB (0) \\
\hline Income & NMS & LVA (4) & $\begin{array}{l}\text { EST (3), CZE (3), SVN (3), ROM } \\
\text { (3), CYP (2) }\end{array}$ & $\begin{array}{l}\text { POL (1), HUN (1), MLT (1), } \\
\text { BUL (1) }\end{array}$ \\
\cline { 2 - 5 } & $\begin{array}{l}\text { Balkan-st. + } \\
\text { Turkey }\end{array}$ & BIH (5), TUR (4); SER (4) & & ALB (1), CRO (0) \\
\hline
\end{tabular}

Source: Country Reports 2009

Note: LIT, SVK, MAC, MON, KOS: no data

Table 5: Assessment of the impact of bio-energy on employment and income in the agricultural and forestry sectors by national experts

\begin{tabular}{|l|l|l|l|l|}
\hline & & \multicolumn{1}{|c|}{ High (4-5) } & \multicolumn{1}{c|}{ Somewhat (2-3) } & \multicolumn{1}{|c|}{ None (0-1) } \\
\hline $\begin{array}{l}\text { Employment } \\
\text { (non-farm) }\end{array}$ & NMS & EST (5) & $\begin{array}{l}\text { LVA (3), CZE (3), HUN (3), } \\
\text { POL (2), SVN (2), MLT (2), } \\
\text { CYP (2), BUL (2), ROM (2) }\end{array}$ & ALB (3), SER (2) \\
\cline { 2 - 5 } & $\begin{array}{l}\text { Balkan-st. + } \\
\text { Turkey }\end{array}$ & TUR (4), BIH (4) & $\begin{array}{l}\text { LVA (3), CYP (3), CZE (2), } \\
\text { HUN (2), SVN (2), MLT (2), } \\
\text { BUL (2) }\end{array}$ & \\
& NMS & EST (5), ROM (4) & ALB (2) & CRO (0) \\
\cline { 2 - 6 } & $\begin{array}{l}\text { Balkan-st. } \\
\text { Turkey }\end{array}$ & BIH (5), TUR (4), SER (4) & & \\
\hline
\end{tabular}

Source: Country Reports 2009

Note: LIT, SVK, MAC, MON, KOS: no data

Table 6: Assessment of the impact of bio-energy on rural development by national experts

representative, statistically. In the following sections, we will focus on two major dimensions: first we look at the impact on the agricultural and forestry sectors in specific and, second, on rural development in general.

In the first round, the national experts were asked whether they would see any employment and income effects in agriculture and forestry with the expansion of biomass production for bio-energy. Their answers were summarised in the national reports on a Likert scale between 0 (not at all) up to 5 (very high). The national findings are summarised in Table 5 . In general, the experts only anticipated a modest employment effect or no effect at all if bio-energy production is expanded in their respective countries. Concerning bio-energy as a potential source of income, the experts in general are a bit more optimistic, particularly in Latvia, Serbia, Bosnia \& Herzegovina and Turkey, but these effects seem to be mostly concentrated on larger farms and forestry owners.

Besides an impact on the agricultural and forestry sectors in particular, the promotion and expansion of bioenergy production might also have an impact on the rural economy in general. Most of the newly established biomass processing plants are already or will be located in rural areas, with the exception of municipal solid waste plants which might have good prospects in mostly urban areas. There might be employment and income effects in building and servicing bio-energy processing plants in the rural areas.

According to expert opinion, bio-energy so far plays a limited role in rural development. Compared to their assessment with respect to the agricultural sector, they seem to be more optimistic about the impact on rural development in general (Table 6). Again, experts seem to see more potential in income than employment effects. While experts in Estonia, Turkey, Bosnia \& Herzegovina and, to some extent in Serbia and Romania, are quite optimistic, Croatian experts are extremely pessimistic. However, national reports are short of providing any rationale for their opinions. If at all, they refer to national programmes, including Rural Development Programmes for 2007-2013 which foresee some financial support for the establishment of bio-energy plants. Therefore, it can be concluded that some modest impact with respect to employment and income will be expected due to an expansion of bio-energy production. Just in Slovakia and Bosnia \& Herzegovina a first estimation with respect to employment effects has been conducted. The estimates for Slovakia are that about 5,000-6,000 additional jobs will be created, if the broader renewable energy targets are met by 2020. Bosnia \& Herzegovina expects about 5,000 new jobs if the country can use just half of its natural potential. But, in total, it is doubtful whether bio-energy 
production in specific or renewable energy production in general will stop the rural-urban migration pattern observed all over the region.

Finally, based on the modest statistical data and expert assessments, it can be concluded that the cultivation of energy crops in general and of rape seed in particular will, in general, create only marginal employment and income effects for most (small scale) farmers in the region. If there are any at all, they will be modest and will not reduce the outmigration rate of farmers. Income effects seem to be observed among larger-scale farmers. This is reflected by the observation that, if farmers do engage in biomass production they are typically larger ones.

\section{Conclusions and Recommendations}

Modern forms of bio-energy are just starting to become a source of energy supply among the countries in Central, Eastern and Southern Europe. In general, their share amount to less than 0.1 percent of total energy demand. In Central Europe alone it stands at about 0.5 percent. But the promotion of bio-energy as one form of renewable energy has become a top political priority all over Europe. All EU member states, including NMS, have adopted national targets aiming at expanding the shares of renewable energy. Some countries among the second group of the study region have started to do the same. These targets have to be met by 2010 and 2020, respectively. Since bio-energy and other forms of renewable energy at this stage of development are economically not competitive with fossil fuels, the EU and most national governments in the region are prepared to provide financial incentives for their promotion. Bioenergy makes up a significant share of total renewable energy and a further expansion is envisaged. The expansion of bio-energy seems to depend on three major factors:

- The political will to designate financial resources for the promotion of the production of bio-energy (i.e. for electricity, heat and/or fuel production) is almost a precondition since bio-energy production is not economically competitive yet. Without state subsidies, mandatory blending requirements and/or high politically-induced feed-in prices, the production would be in a pilot stage only and play no role at all in meeting total energy demand. Owing to co-financing, a large part of that burden is taken over by the EU with respect to the NMS, but nevertheless a certain share has to be financed by national budgets and/or consumers. So the expansion of bio-energy production is restricted by the available financial resources. Otherwise, interested entrepreneurs are frightened off by the high initial investment costs and the non-cost-covering market prices.

- The natural conditions of some countries seem to favour one source of bio-energy over another. Countries in Northern and Central Europe are more favoured in producing biomass than countries in Southern Europe due to more favourable precipitation patterns. Besides annual crops they can make use of wood and wood products on a larger scale than the drier and hotter regions in Southern Europe. As a result, we conclude that while a mix of various sources of bio-energy production might be desirable to diversify risks, regions will ultimately specialise in those sources that are best adjusted to the respective natural conditions.

- Finally, the social repercussions of bio-energy production become evident in most countries of the region. Most are dominated by small-scale farming and forestry. In order to produce the needed biomass for processing a certain minimum size seems to be a prerequisite. Hence, most farmers and forestry owners cannot participate in this new type of farm and forestry activity. A way out might be better organisation of interested small-scale producers in self-help groups or cooperatives, but most farmers of the study region are still reluctant to join these types of organisations.

By way of summary, it can be concluded that for the near future the overall employment and income effects of an expansion of bio-energy production among the agricultural and forestry sectors as well as in rural regions in general will be very modest. In this respect, we recommend that the EU and national governments not only place emphasis on high prices, tariffs and mandatory blending, but also ensure that (small-scale) farmers and forestry owners can benefit from this development. This requires not only more focused extension and better access to financial services, but particularly targeted support in organising (small-scale) farmers and forestry owners. 무 


\section{References}

Bederac, M. and T. Cunder (2009). Analysis of Renewable Energy and its Impact on Rural Development in Slovenia. Paris, France: 'Enlargement Network for Agricultural Policy Analysis', FP7 (www.agripolicy.net).

Bogunovic, A. and N. Bogdanov (2009). Analysis of Renewable Energy and its Impact on Rural Development in Serbia. Paris, France: 'Enlargement Network for Agricultural Policy Analysis', FP7 (www.agripolicy.net).

Bozhidar, I. and R. Popov (2009). Analysis of Renewable Energy and its Impact on Rural Development in Bulgaria. Paris, France: 'Enlargement Network for Agricultural Policy Analysis', FP7 (www.agripolicy.net).

Budak, D.B. (2009). Analysis of Renewable Energy and its Impact on Rural Development in Turkey. Paris, France: 'Enlargement Network for Agricultural Policy Analysis', FP7 (www.agripolicy.net).

Cela, R. and A. Himez (2009). Analysis of Renewable Energy and its Impact on Rural Development in Albania. Paris, France: 'Enlargement Network for Agricultural Policy Analysis', FP7 (www.agripolicy.net).

Cerjak, M. (2009). Analysis of Renewable Energy and its Impact on Rural Development in Croatia. Paris, France: 'Enlargement Network for Agricultural Policy Analysis', FP7 (www.agripolicy.net).

Dimitrievski, D. and A. Kostevska (2009). Analysis of Renewable Energy and its Impact on Rural Development in Macedonia. Paris, France: 'Enlargement Network for Agricultural Policy Analysis', FP7 (www.agripolicy.net).

Eicaite, O. and A. Gapsys (2009). Analysis of Renewable Energy and its Impact on Rural Development in Lithuania. Paris, France: 'Enlargement Network for Agricultural Policy Analysis', FP7 (www.agripolicy.net).

European Biodiesel Board (2009). Production Figures. Agra Europe: Agra Facts. No. 56, Bonn, 15 July 2009.

EUROSTAT (2009a). The Eurostat Concepts and Definitions Database http://circa.europa.eu/irc/dsis/coded/info/data/coded/en/Theme9.htm (3 August 2009)

EUROSTAT (2009b): Statistical Data on Renewable Energy http://epp.eurostat.ec.europa.eu/portal/page/portal/energy/data/datab ase (July and August 2009)

Firenczi, T., C. Forgacs and T. Mizik (2009). Analysis of Renewable Energy and its Impact on Rural Development in Hungary. Paris, France: 'Enlargement Network for Agricultural Policy Analysis', FP7 (www.agripolicy.net).

Florianczyk, Z., A. Wasilewska, G. Kunikowski and P. Gradziuk (2009). Analysis of Renewable Energy and its Impact on Rural Development in Poland. Paris, France: 'Enlargement Network for Agricultural Policy Analysis', FP7 (www.agripolicy.net).

Ibra, M. (2009). Analysis of Renewable Energy and its Impact on Rural Development in Kosovo. Paris, France: 'Enlargement Network for Agricultural Policy Analysis', FP7 (www.agripolicy.net).

loannou, T. and D. Theocharides (2009). Analysis of Renewable Energy and its Impact on Rural Development in Cyprus. Paris, France: 'Enlargement Network for Agricultural Policy Analysis', FP7 (www.agripolicy.net).

Istvan, P. and T. Ervin (2009). Analysis of Renewable Energy and its Impact on Rural Development in Romania. Paris, France: 'Enlargement Network for Agricultural Policy Analysis', FP7 (www.agripolicy.net).

Krievina, A. (2009). Analysis of Renewable Energy and its Impact on Rural Development in Latvia. Paris, France: 'Enlargement Network for Agricultural Policy Analysis', FP7 (www.agripolicy.net).
Markovic, M., B. Markovic, M. Andjelic and J. Knezevic (2009). Analysis of Renewable Energy and its Impact on Rural Development in Montenegro. Paris, France: 'Enlargement Network for Agricultural Policy Analysis', FP7 (www.agripolicy.net).

Masar, I. (2009). Analysis of Renewable Energy and its Impact on Rural Development in Slovakia. Paris, France: 'Enlargement Network for Agricultural Policy Analysis', FP7 (www.agripolicy.net).

Nikolic, A., S. Bajramovic and D. Ognjenovic (2009). Analysis of Renewable Energy and its Impact on Rural Development in Bosnia and Herzegovina. Paris, France: 'Enlargement Network for Agricultural Policy Analysis', FP7 (www.agripolicy.net).

Ostermeyer, A. and F. Pirscher (2010). Potenzial von Bioenergie in Deutschland - Studien im Vergleich. Berichte über Landwirtschaft 88 (2), 247-274.

Sammut, S. (2009). Analysis of Renewable Energy and its Impact on Rural Development in Malta. Paris, France: 'Enlargement Network for Agricultural Policy Analysis', FP7 (www.agripolicy.net).

Sepp, M. (2009). Analysis of Renewable Energy and its Impact on Rural Development in Estonia. Paris, France: 'Enlargement Network for Agricultural Policy Analysis', FP7 (www.agripolicy.net).

Weichet, J. (2009). Analysis of Renewable Energy and its Impact on Rural Development in the Czech Republic. Paris, France: 'Enlargement Network for Agricultural Policy Analysis', FP7 (www.agripolicy.net).

White, B. and A. Dasgupta (2010). Agrofuels capitalism: a view from political economy. Journal of Peasant Studies 37 (4), 593-607.

Wolz, A., G. Buchenrieder and R. Markus (2009). Synthesis of the Country Reports on Renewable Energy and its Impact on Rural Development in the New Member States, Candidate and Potential Candidate Countries. Paris, France: 'Enlargement Network for Agricultural Policy Analysis', FP7 (www.agripolicy.net).

Zeller, M. and M. Grass (2008). Agrofuel boom or doom? Opportunities and constraints for agrofuels in developing countries. Quarterly Journal of International Agriculture 47 (4), 285-305. 